\title{
ИССЛЕДОВАНИЕ ДИНАМИКИ УРОВНЯ ФИЗИЧЕСКОЙ ПОДГОТОВЛЕННОСТИ СТУДЕНТОВ АГРАРНОГО ВУЗА К СДАЧЕ НОРМАТИВОВ КОМПЛЕКСА «ГТО» В ПРОЦЕССЕ ОБУЧЕНИЯ
}

\author{
С.Д. Глазуненко (фото) \\ старший преподаватель кафедры гуманитарных дисциплин \\ Г.И. Плющев \\ старший преподаватель кафедры гуманитарных дисциплин \\ ФГБОУ ВО Ярославская ГСХА, г. Ярославль
}

\section{Уровень физической подготовленности обучающихся, комплекс «ГТО», норматив}

The level of physical fitness of students, Complex "GTO", standard
Важным средством физического и морального воспитания молодежи в нашей стране, начиная с 30-х годов прошлого века, стал разработанный комплекс «Готов к труду и обороне СССР» (ГТО), который был утверждён 11 марта 1931 года Всесоюзным советом физической культуры при Центральном исполнительном Комитете СССР.

За годы существования комплекса практически все поколения советских людей прошли через «ГТО».

В связи с историческими событиями изменялся и комплекс «ГТО»: в 1991 году он был отменён, в 2014 году опять стали проводить исследования в этом направлении, и после уточнения нормативов в 2018 году начал действовать «новый» комплекс «ГТО». Он предусматривает выполнение различными возрастными группами (от 6 до 70 лет и старше) определённых нормативных требований по трём уровням интегральных трудностей, соответствующих «золотому», «серебряному» и «бронзовому» значкам «Готов к труду и обороне» (ГТО) [1, 2].

Внедрение комплекса ГТО в процесс физического воспитания обучающихся позволяет, на наш взгляд, определять уровень их физического здоровья и работоспособности, более осмысленно строить цели и задачи при проведении занятий по физической культуре и спорту, а также способствует повышению роли физической культуры в здоровом образе жизни молодёжи.

Цель нашего исследования заключалась в изучении динамики уровня подготовленности обучающихся аграрного вуза с 1-го по 3-й курсы на примере ФГБОУ ВО Ярославская ГСХА к сдаче нормативов комплекса «ГТО». 


\section{Организация и методы исследования}

На первом этапе исследования нами были использованы методы педагогического эксперимента и наблюдения, разработанные нами методики [3], а также непосредственно сам комплекс «ГTO» [4].

Из всех контрольных упражнений комплекса «ГТО» нами был разработан блок тестовых заданий, наиболее точно характеризующий уровень подготовленности обучающихся по данной системе: сгибание-разгибание рук в упоре; подтягивание на перекладине; наклоны вперёд, стоя на скамейке; прыжки с места двумя ногами; кросс (3/2 км); бег на 100 метров; челночный бег (3×10 метров); метание гранаты. Все упражнения выполнялись по правилам физкультурно-спортивного комплекса «ГТО».

В мониторинге физической подготовленности к сдаче комплекса «ГТО» участвовали обучающиеся ФГБОУ ВО Ярославская ГСХА (юноши и девушки) с 1-го по 3-й курсы основной медицинской группы с сентября 2018 года по май 2019 года; для получения достоверных результатов сдача нормативов проводилась в соревновательной форме. Величина выборки составила 100 результатов по каждому виду тестирования.

Оценка тестовых нормативов осуществлялась по пятибалльной системе, каждому баллу соответствовал очковый эквивалент выполнения комплекса «ГТО».

Так, 5 баллов соответствует нормативам «золотого» значка (21 очко), 4 балла - «серебряного» значка (11 очков), 3 балла - «бронзового» значка (6 очков) (табл. 1).

Результаты тестирования обучающихся, набравших от 1 до 6 очков, соответствовали уровню «неудовлетворительному», от 6 до 11 очков - «удовлетворительному», от 11 до 16 очков - «хорошему», от 16 до 21 очка - «очень хорошему», от 21 до 25 «отличному». Для эквивалентности результатов в различных видах упражнений мы использовали пропорциональное деление результатов между границами оценок.

Используя методику создания центильной таблицы Н.В. Решетникова [5] и методику создания сигмовидной 50-очковой таблицы оценки физической подготовленности студентов [6], мы разработали комплексную сигмовидную 25-очковую таблицу для обработки результатов тестирования, позволяющую определить уровень физический подготовленности обучающихся к выполнению нормативов комплекса ГТО (табл. 2).

В результате математико-статистической обработки выполнения обучающимися нормативов комплекса «ГТО» были определены средние зна-

Таблица 1 - Оценка физической подготовленности обучающихся по пятибалльной системе согласно нормативам комплекса «ГТО»

\begin{tabular}{|c|c|c|c|c|c|c|c|c|c|c|}
\hline \multirow{3}{*}{ Вид упражнения комплекса «ГТО» } & \multicolumn{10}{|c|}{ Балл } \\
\hline & \multicolumn{2}{|c|}{5} & \multicolumn{2}{|c|}{4} & \multicolumn{2}{|c|}{3} & \multicolumn{2}{|c|}{2} & \multicolumn{2}{|c|}{1} \\
\hline & ю & д & ю & д & ю & д & Ю & д & Ю & д \\
\hline $\begin{array}{l}\text { Сгибание-разгибание рук } \\
\text { в упоре (юноши - от пола, } \\
\text { девушки - от скамейки), раз }\end{array}$ & 44 & 17 & 32 & 12 & 28 & 10 & 22 & 7 & 18 & 5 \\
\hline $\begin{array}{l}\text { Подтягивание на перекладине } \\
\text { (девушки - из виса стоя } 90 \text { см), } \\
\text { раз }\end{array}$ & 15 & 18 & 12 & 12 & 10 & 10 & 7 & 7 & 5 & 5 \\
\hline $\begin{array}{l}\text { Гибкость (наклоны вперёд, стоя } \\
\text { на скамейке), см }\end{array}$ & 13 & 16 & 8 & 11 & 6 & 6 & 2 & 2 & 0 & 0 \\
\hline Прыжки с места двумя ногами, см & 240 & 195 & 225 & 180 & 210 & 170 & 197 & 160 & 190 & 150 \\
\hline $\begin{array}{l}\text { Кросс (юноши - } 3 \text { км, девушки - } \\
2 \text { км), мин }\end{array}$ & 12,00 & 10,50 & 13,40 & 12,30 & 14,30 & 13,10 & 15,00 & 13,40 & 15,20 & 14,00 \\
\hline Бег 100 метров, с & 15,1 & 16,5 & 14,8 & 17,0 & 15,1 & 17,5 & 15,7 & 18,1 & 16,0 & 18,5 \\
\hline $\begin{array}{l}\text { Челночный бег с высокого старта } \\
(3 \times 10 \text { м), с }\end{array}$ & 7,1 & 8,2 & 7,7 & 8,8 & 8,0 & 9,0 & 8,8 & 9,6 & 9,2 & 10,0 \\
\hline Метание гранаты, м & 37 & 21 & 35 & 17 & 33 & 14 & 27 & 11 & 23 & 9 \\
\hline Очки & \multicolumn{2}{|c|}{21} & \multicolumn{2}{|c|}{11} & \multicolumn{2}{|c|}{6} & \multicolumn{2}{|c|}{3} & \multicolumn{2}{|c|}{1} \\
\hline
\end{tabular}

Исследование динамики уровня физической подготовленности студентов аграрного вуза к сдаче нормативов комплекса «ГТО» в процессе обучения 
Таблица 2 - Оценка физической подготовленности обучающихся к сдаче нормативов комплекса «ГТО» по видам тестирования в очковом эквиваленте

\begin{tabular}{|c|c|c|c|c|c|c|c|c|c|c|c|c|c|c|c|c|}
\hline \multirow[t]{2}{*}{ 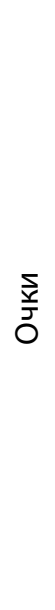 } & \multicolumn{2}{|c|}{ 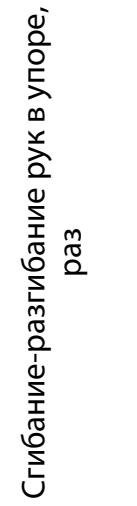 } & \multicolumn{2}{|c|}{ 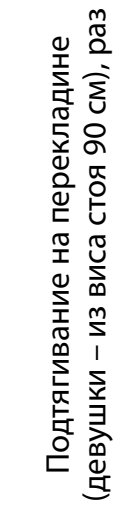 } & \multicolumn{2}{|c|}{ 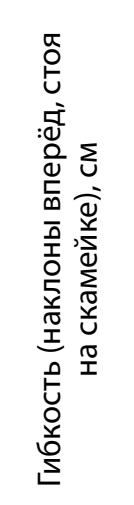 } & \multicolumn{2}{|c|}{ 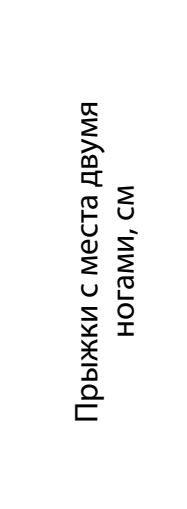 } & \multicolumn{2}{|c|}{ 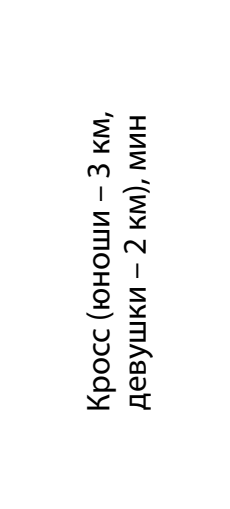 } & \multicolumn{2}{|c|}{ 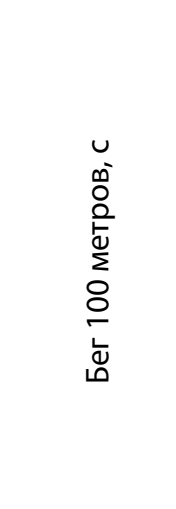 } & \multicolumn{2}{|c|}{ 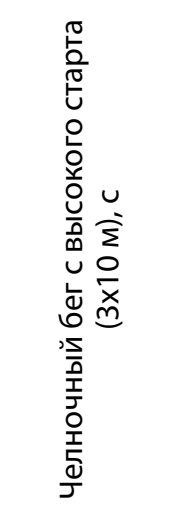 } & \multicolumn{2}{|c|}{ 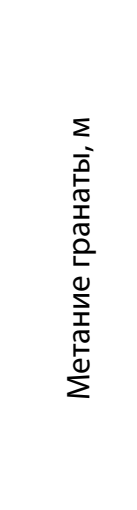 } \\
\hline & ю & д & ю & д & ю & д & ю & д & ю & д & ю & д & ю & д & ю & A \\
\hline 1 & 18 & 5 & 5 & 5 & 0 & 0 & 190 & 150 & 15,20 & 14,00 & 16,0 & 18,5 & 9,2 & 10,0 & 23 & 9 \\
\hline 2 & 20 & 6 & 6 & 6 & 1 & 1 & 193 & 154 & 15,10 & 13,50 & 16,9 & 18,3 & 9,0 & 9,8 & 25 & 10 \\
\hline 3 & 22 & 7 & 7 & 7 & 2 & 2 & 197 & 160 & 15,00 & 13,40 & 15,7 & 18,1 & 8,8 & 9,6 & 27 & 11 \\
\hline 4 & 24 & 8 & 8 & 8 & 3 & 3 & 201 & 163 & 14,50 & 13,30 & 15,5 & 17,9 & 8,6 & 9,4 & 29 & 12 \\
\hline 5 & 26 & 9 & 9 & 9 & 4 & 4 & 206 & 167 & 14,40 & 13,20 & 15,3 & 17,7 & 8,2 & 9,2 & 32 & 13 \\
\hline 6 & 28 & 10 & 10 & 10 & 6 & 6 & 210 & 170 & 14,30 & 13,10 & 15,1 & 17,5 & 8,0 & 9,0 & 33 & 14 \\
\hline 7 & 29 & & & & & & 213 & 172 & 14,20 & 13,05 & & 17,4 & 7,9 & & & 15 \\
\hline 8 & 30 & 11 & 11 & 11 & 7 & 7 & 216 & 174 & 14,10 & 13,00 & 15,0 & 17,3 & & 8,9 & 34 & \\
\hline 9 & 31 & & & & & 8 & 219 & 176 & 14,00 & 12,50 & & 17,2 & 7,8 & & & 16 \\
\hline 10 & & & & & & 9 & 222 & 178 & 13,50 & 12,40 & 14,9 & 17,1 & & & & \\
\hline 11 & 32 & 12 & 12 & 12 & 8 & 11 & 225 & 180 & 13,40 & 12,30 & 14,8 & 17,0 & 7,7 & 8,8 & 35 & 17 \\
\hline 12 & 33 & & & & & & 226 & 181 & 13,30 & 12,20 & 14,7 & 10,4 & 7,6 & 8,7 & & \\
\hline 13 & 34 & 13 & & 13 & 9 & 12 & 227 & 182 & 13,20 & 12,10 & 14,6 & 16,9 & 7,5 & 8,6 & & 18 \\
\hline 14 & 35 & & 13 & & & & 228 & 183 & 13,10 & 12,00 & 14,5 & & & & & \\
\hline 15 & 36 & 14 & & 14 & 10 & 13 & 229 & 184 & 13,00 & 11,50 & 14,4 & 16,8 & 7,4 & 8,5 & & 19 \\
\hline 16 & 38 & & & & & & 230 & 185 & 12,50 & 11,40 & 14,3 & & & & 36 & \\
\hline 17 & 39 & 15 & 14 & 15 & 11 & 14 & 232 & 187 & 12,40 & 11,30 & 14,2 & 16,7 & 7,3 & 8,4 & & \\
\hline 18 & 40 & & & & & & 234 & 189 & 12,30 & 11,20 & 11,2 & 14,1 & & & & 20 \\
\hline 19 & 41 & 16 & & 17 & 12 & 15 & 236 & 191 & 12,20 & 11,10 & 13,9 & 16,6 & 7,2 & 8,3 & & \\
\hline 20 & 42 & & & & & & 238 & 193 & 12,10 & 11,00 & 13,7 & & & & & \\
\hline 21 & 44 & 17 & 15 & 18 & 13 & 16 & 240 & 195 & 12,00 & 10,50 & 13,5 & 16,5 & 7,1 & 8,2 & 37 & 21 \\
\hline 22 & 47 & 20 & 18 & 21 & 16 & 19 & 245 & 200 & 11,40 & 10,30 & 13,2 & 16,2 & 6,9 & 7,9 & 40 & 24 \\
\hline 23 & 50 & 23 & 21 & 24 & 19 & 22 & 250 & 205 & 11,20 & 10,10 & 12,7 & 15,7 & 6,6 & 7,6 & 43 & 27 \\
\hline 24 & 54 & 26 & 24 & 27 & 22 & 25 & 255 & 210 & 11,00 & 9,50 & 12,2 & 15,2 & 6,3 & 7,3 & 46 & 31 \\
\hline 25 & 60 & 30 & 27 & 30 & 24 & 27 & 260 & 215 & 10,30 & 9,20 & 11,5 & 14,5 & 6,0 & 7,0 & 50 & 35 \\
\hline
\end{tabular}


чения полученных результатов по отдельным видам упражнений (табл. 3).

По данным таблицы 3 определили уровень физической подготовленности обучающихся к сдаче нормативов комплекса «ГТО» в отдельных видах упражнений. Так, уровень подготовленности юношей 3 курса к сдаче нормативов комплекса «ГТО» оказался выше 2-го и 1-го курсов на 8,9 и

Таблица 3 - Средние значения результатов выполнения обучающимися ФГБОУ ВО Ярославская ГСХА отдельных видов нормативов комплекса «ГТО»

\begin{tabular}{|l|c|c|c|c|c|c|}
\hline \multirow{2}{*}{ Наименование контрольного упражнения } & \multicolumn{3}{|c|}{ Юноши } & \multicolumn{3}{|c|}{ Девушки } \\
\cline { 2 - 6 } & 1 курс & 2 курс & 3 курс & 1 курс & 2 курс & 3 курс \\
\hline $\begin{array}{l}\text { Сгибание-разгибание рук в упоре: юноши } \\
\text { от пола, девушки от скамейки, раз }\end{array}$ & $34 / 13$ & $35 / 14$ & $37 / 15$ & $12 / 11$ & $13 / 13$ & $14 / 15$ \\
\hline $\begin{array}{l}\text { Подтягивание на перекладине верхним } \\
\text { хватом: юноши на высокой перекладине, } \\
\text { девушки - из виса лёжа (90 см), раз }\end{array}$ & $8 / 4$ & $9 / 5$ & $10 / 6$ & $8 / 4$ & $9 / 5$ \\
\hline $\begin{array}{l}\text { Упражнение на гибкость, стоя на гимнасти- } \\
\text { ческой скамейке наклон вперёд - ладонями } \\
\text { ниже уровня скамейки, см }\end{array}$ & $7 / 8$ & $8 / 11$ & $7 / 8$ & $10 / 10$ & $12 / 13$ & $13 / 15$ \\
\hline Прыжки в длину с места двумя ногами, см & $221 / 10$ & $224 / 10$ & $226 / 12$ & $171 / 6$ & $167 / 5$ & $163 / 4$ \\
\hline Кросс: юноши - З км, девушки - 2 км, мин & $13,17 / 13$ & $13,14 / 13$ & $13,10 / 14$ & $12,28 / 13$ & $12,37 / 10$ & $12,45 / 9$ \\
\hline Бег на 100 метров с низкого старта, с & $14,9 / 10$ & $14,8 / 11$ & $14,5 / 14$ & $17,4 / 7$ & $17,1 / 10$ & $17,3 / 8$ \\
\hline Челночный бег (3х10 м) с высокого старта, с & $7,6 / 12$ & $7,4 / 15$ & $7,5 / 13$ & $8,6 / 13$ & $8,8 / 11$ & $8,9 / 8$ \\
\hline Метание гранаты с разбега, м & $34 / 8$ & $35 / 11$ & $36 / 16$ & $14 / 6$ & $15 / 7$ & $17 / 11$ \\
\hline Сумма очков & 78 & 90 & 98 & 70 & 74 & 76 \\
\hline
\end{tabular}

25,6\% соответственно. У девушек также наблюдается положительная динамика уровня подготовленности к сдаче нормативов комплекса «ГТО» от 1-го к 3-му курсу.

Далее определили критерии интегрального индекса подготовленности студентов к сдаче нормативов комплекса «ГТО» (табл. 4). Для выполнения нормативов «бронзового» значка (средний уровень) обучающийся должен набрать 48-87 очков в восьми контрольных испытаниях (тестах), «серебряного» значка - 88-127 очков, а «золотого» значка -168-200 очков.

Сопоставляя результаты выполнения обучающимися ФГБОУ ВО Ярославская ГСХА отдельных видов нормативов комплекса «ГТО» (табл. 3) с результатами данных таблицы 4, можно увидеть, что в среднем юноши и девушки 1-го курса имели средний уровень подготовленности к сдаче нормативов комплекса «ГТО», что соответствовало нормативам «бронзового» значка. Юноши 2-го и

Таблица 4 - Критерии интегрального индекса физической подготовленности обучающихся к сдаче нормативов комплекса «ГТО»

\begin{tabular}{|c|c|c|}
\hline $\begin{array}{c}\text { Оценка (в баллах) сдачи } \\
\text { нормативов комплекса «ГТО» }\end{array}$ & Интервал очков & $\begin{array}{c}\text { Критерии интегрального индекса физической } \\
\text { подготовленности к сдаче нормативов комплекса «ГТО» }\end{array}$ \\
\hline 1 балл & $8-23$ & Низкий \\
\hline 2 балла & $24-47$ & Ниже среднего \\
\hline 3 балла & $48-87$ & Средний («бронзовый» значок) \\
\hline 4 балла & $88-127$ & Выше среднего («серебряный» 3начок) \\
\hline $4+$ балла & $128-167$ & Высокий (переходный) \\
\hline 5 баллов & $168-200$ & Очень высокий («золотой» значок) \\
\hline
\end{tabular}

Исследование динамики уровня физической подготовленности студентов аграрного вуза к сдаче нормативов комплекса «ГТО» в процессе обучения 
3-го курсов в динамике улучшили свои результаты и имели уровень готовности выше среднего («серебряный» значок»), а девушки этих же кур- сов в среднем практически остались на прежнем уровне подготовленности к сдаче нормативов комплекса «ГТО» (табл. 5).

Таблица 5 - Уровень подготовленности обучающихся ФГБОУ ВО Ярославская ГСХА к сдаче нормативов комплекса «ГТО»

\begin{tabular}{|c|c|c|c|}
\hline $\begin{array}{c}\text { Курс } \\
\text { обучения }\end{array}$ & $\begin{array}{l}\text { Характеристика } \\
\text { обучающихся }\end{array}$ & $\begin{array}{c}\text { Результат } \\
\text { выполнения } \\
\text { нормативов } \\
\text { комплекса } \\
\text { «ГТ», очки }\end{array}$ & $\begin{array}{c}\text { Интегральный уровень подготовленности } \\
\text { к сдаче нормативов комплекса «ГТО» }\end{array}$ \\
\hline \multirow{2}{*}{ I } & Юноши & 78 & Средний («бронзовый» значок) \\
\hline & Девушки & 70 & Средний («бронзовый» значок) \\
\hline \multirow{2}{*}{ II } & Юноши & 90 & Выше среднего («серебряный» значок) \\
\hline & Девушки & 74 & Средний («бронзовый» значок) \\
\hline \multirow{2}{*}{ III } & Юноши & 98 & Выше среднего («серебряный» значок) \\
\hline & Девушки & 76 & Средний («бронзовый» значок) \\
\hline
\end{tabular}

\section{Выводы}

Мониторинг физической подготовленности обучающихся 1-3 курсов основной медицинской группы аграрного вуза в 2018-2019 гг. показал, что интегральный уровень подготовленности юношей к сдаче нормативов комплекса «ГТО» с 1-го по 3-й курс повысился со «среднего» («бронзовый» значок) до «выше среднего» («серебряный» значок), а у девушек остался практически на прежнем уровне, с небольшой тенденцией роста («бронзовый» значок).

Разработанная нами методика может быть использована в процессе подготовки студентов к сдаче нормативов комплекса «ГТО». Она позволяет определить уровень физической подготовленности и различных физических качеств обучающихся, что даёт возможность вносить коррективы в организацию учебного процесса.

Использование в учебном процессе аграрных вузов нормативов Всероссийского физкультурно-спортивного комплекса «Готов к труду и обороне», на наш взгляд, будет способствовать созданию эффективной системы физического воспитания и укрепления здоровья будущих выпускников, а, соответственно, специалистов для агропромышленного комплекса страны.

\section{תumepamypa}

1. Потупчик, Т.В. Функциональная готовность студентов к сдаче нормативов ГТО [Текст] / Т.В. Потупчик, Л.С. Эверт, О.В. Аверьянова // Здоровье и образование в XXI веке. - 2016. - Т. 18. - № 6. - С. 38-40.

2. Указ Президента РФ от 24 марта 2014 г. № 172 «О Всероссийском физкультурно-спортивном комплексе «Готов к труду и обороне» (ГТО)» [Электронный ресурс]. - Режим доступа: https://www.minsport. gov.ru/documents/orders/29073/.

3. Глазуненко, С.Д. Методика оценки показателей физической подготовленности студентов, обучающихся в сельскохозяйственных вузах [Текст] / С.Д. Глазуненко, Г.И. Плющев // Проблемы применения здоровьесберегающих технологий на занятиях физической культурой: сб. науч. тр. по материалам Региональной науч.-практ. конф. - Ярославль: Изд-во ФГБОУ ВО Ярославская ГСХА, 2018. - С. 40-47.

4. Официальный сайт Всесоюзного физкультурного спортивного комплекса «Готов к труду и обороне» (ГТО) [Электронный ресурс]. - Режим доступа: https://www.gto.ru/feedback.

5. Решетников, Н.В. Таблица оценки физической подготовленности студентов [Текст] / Н.В. Решетников // Теория и практика физической культуры. - 2014. - № 4. - С. 37-41.

6. Глазуненко, С.Д. Методика исследования динамики физической подготовленности студентов в процессе обучения с 1 по 3 курс [Текст] / С.Д. Глазуненко, Г.И. Плющев // Актуальные проблемы физической культуры и спорта в современных социально-экономических условиях: материалы Международ. науч.практ. конф., посвященной 100-летию Национального Университета Узбекистана имени Мирзо Улугбека. 2018. - C. 132-138. 


\section{References}

1. Potupchik, T.V. Funkcional'naja gotovnost' studentov k sdache normativov GTO [Tekst] / T.V. Potupchik, L.S. Ehvert, O.V. Aver'yanova // Zdorov'e i obrazovanie v XXI veke. - 2016. - T. 18. - № 6. - S. 38-40.

2. Ukaz Prezidenta RF ot 24 marta 2014 g. № 172 «O Vserossijskom fizkul'turno-sportivnom komplekse «Gotov k trudu i oborone»(GTO)» [Jelektronnyj resurs]. - Rezhim dostupa: https://www.minsport.gov.ru/ documents/orders/29073/.

3. Glazunenko, S.D. Metodika ocenki pokazatelej fizicheskoj podgotovlennosti studentov, obuchajushhihsja v sel'skohozjajstvennyh vuzah [Tekst] / S.D. Glazunenko, G.I. Plyushchev // Problemy primenenija zdorov'esberegajushhih tehnologij na zanjatijah fizicheskoj kul'turoj: sb. nauch. tr. po materialam Regional'noj nauch.-prakt. konf. - Jaroslavl': Izd-vo FGBOU VO Jaroslavskaja GSHA, 2018. - S. 40-47.

4. Oficial'nyj sajt Vsesojuznogo fizkul'turnogo sportivnogo kompleksa «Gotov k trudu i oborone» (GTO) [Jelektronnyj resurs]. - Rezhim dostupa: https://www.gto.ru/feedback.

5. Reshetnikov, N.V. Tablica ocenki fizicheskoj podgotovlennosti studentov [Tekst] / N.V. Reshetnikov // Teorija i praktika fizicheskoj kul'tury. - 2014. - № 4. - S. 37-41.

6. Glazunenko, S.D. Metodika issledovanija dinamiki fizicheskoj podgotovlennosti studentov $v$ processe obuchenija s 1 po 3 kurs [Tekst] / S.D. Glazunenko, G.l. Plyushchev // Aktual'nye problemy fizicheskoj kul'tury i sporta v sovremennyh social'no-jekonomicheskih uslovijah: materialy Mezhdunarod. nauch.-prakt. konf., posvjashhennoj 100-letiju Nacional'nogo Universiteta Uzbekistana imeni Mirzo Ulugbeka. - 2018. - S. 132-138.

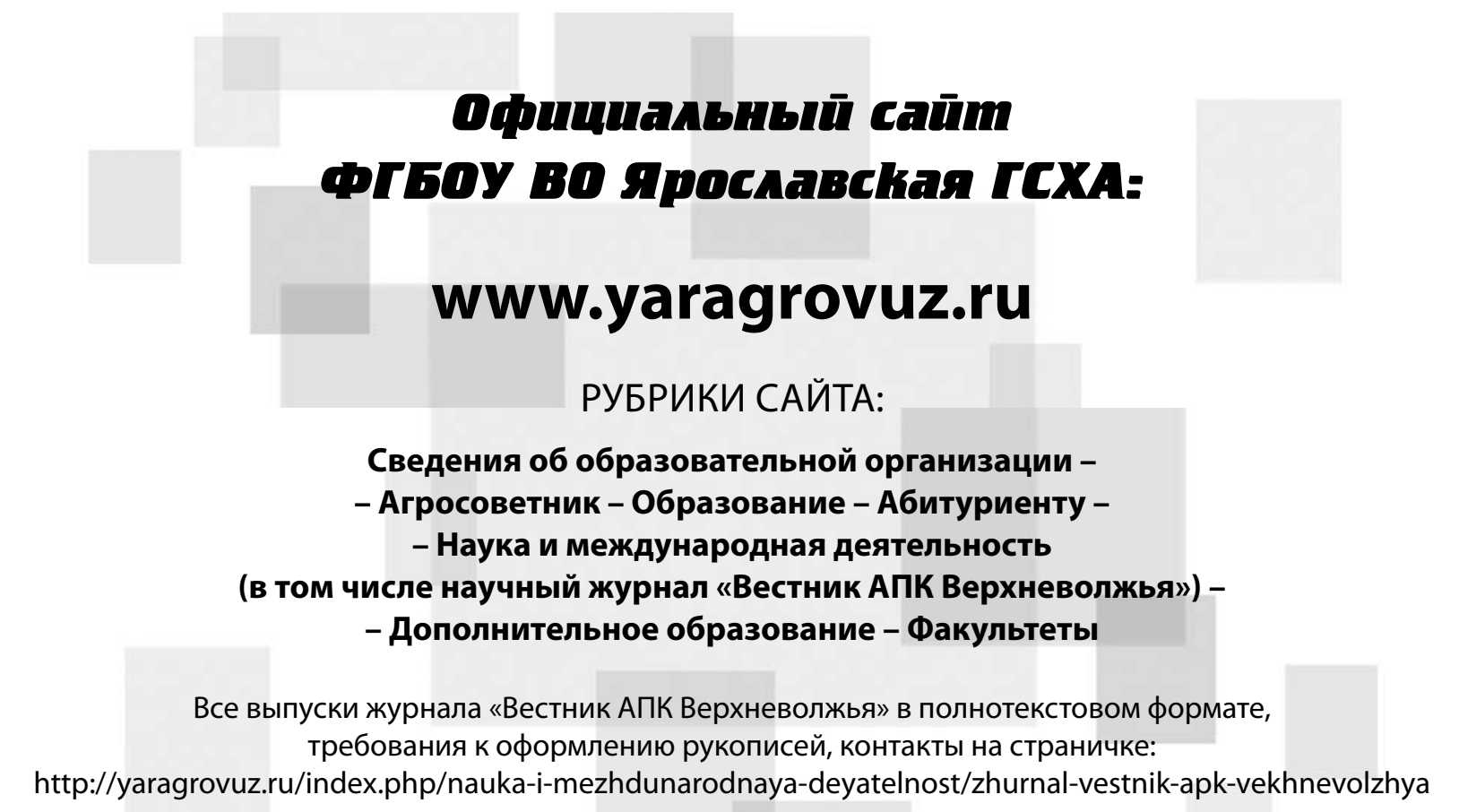

